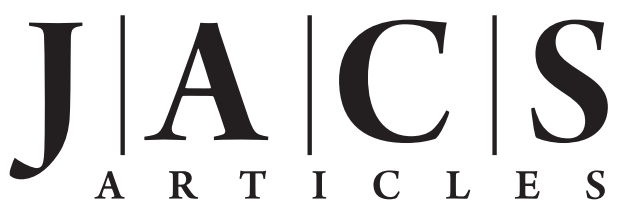

Published on Web 12/16/2010

\title{
Improving a Natural Enzyme Activity through Incorporation of Unnatural Amino Acids
}

\author{
Isaac N. Ugwumba, ${ }^{\dagger, \ddagger}$ Kiyoshi Ozawa, ${ }^{\ddagger, \S}$ Zhi-Qiang Xu, ${ }^{\dagger, \S}$ Fernanda Ely," \\ Jee-Loon Foo, ${ }^{\ddagger}$ Anthony J. Herlt, ${ }^{\ddagger}$ Chris Coppin, ${ }^{\dagger}$ Sue Brown, ${ }^{\dagger}$ Matthew C. Taylor ${ }^{\dagger}$ \\ David L. Ollis, ${ }^{\ddagger}$ Lewis N. Mander, ${ }^{\ddagger}$ Gerhard Schenk, ${ }^{\prime \prime \perp}$ Nicholas E. Dixon, ${ }^{\S}$ \\ Gottfried Otting, ${ }^{\ddagger}$ John G. Oakeshott, ${ }^{\dagger}$ and Colin J. Jackson, ${ }^{\star,+, \ddagger}$ \\ Commonwealth Scientific and Industrial Research Organization, Black Mountain, Canberra, Australia, \\ Research School of Chemistry, Australian National University, Canberra, Australia, School of Chemistry, \\ University of Wollongong, Australia, School of Chemistry and Molecular Biosciences, University of \\ Queensland, Australia, Department of Chemistry, National University of Ireland - Maynooth, Ireland
}

Received August 1, 2010; E-mail: cjackson@rsc.anu.edu.au

\begin{abstract}
The bacterial phosphotriesterases catalyze hydrolysis of the pesticide paraoxon with very fast turnover rates and are thought to be near to their evolutionary limit for this activity. To test whether the naturally evolved turnover rate could be improved through the incorporation of unnatural amino acids and to probe the role of peripheral active site residues in nonchemical steps of the catalytic cycle (substrate binding and product release), we replaced the naturally occurring tyrosine amino acid at position 309 with unnatural $L$-(7-hydroxycoumarin-4-yl)ethylglycine (Hco) and L-(7-methylcoumarin-4-yl)ethylglycine amino acids, as well as leucine, phenylalanine, and tryptophan. Kinetic analysis suggests that the 7-hydroxyl group of Hco, particularly in its deprotonated state, contributes to an increase in the rate-limiting product release step of substrate turnover as a result of its electrostatic repulsion of the negatively charged 4-nitrophenolate product of paraoxon hydrolysis. The 8-11-fold improvement of this already highly efficient catalyst through a single rationally designed mutation using an unnatural amino acid stands in contrast to the difficulty in improving this native activity through screening hundreds of thousands of mutants with natural amino acids. These results demonstrate that designer amino acids provide easy access to new and valuable sequence and functional space for the engineering and evolution of existing enzyme functions.
\end{abstract}

\section{Introduction}

The development of experimental techniques that allow incorporation of unnatural amino acids $(u A A s)$ into proteins has opened new avenues in protein engineering and characterization of protein function, permitting the synthesis of a wide range of unnatural enzymes with new or improved activities and novel mechanistic probes. ${ }^{1-4}$ Methods for translational incorporation of $u A A$ s can be broadly separated into global and specific approaches. Global approaches exploit either natural misacylation of tRNA by close structural analogues based on the substrate promiscuity of existing tRNA synthetases, ${ }^{5}$ or utilize chemical misacylation, ${ }^{6}$ to allow incorporation of $u A A$ s in place

* To whom correspondence should be addressed.

Commonwealth Scientific and Industrial Research Organization.

* Australian National University.

$\$$ University of Wollongong.

"University of Queensland.

${ }^{\perp}$ National University of Ireland - Maynooth.

(1) Connor, R. E.; Tirrell, D. A. Polymer Rev. 2007, 47, 9-28.

(2) Hendrickson, T. L.; de Crecy-Lagard, V.; Schimmel, P. Annu. Rev. Biochem. 2004, 73, 147-176.

(3) Wang, L.; Xie, J.; Schultz, P. G. Annu. Rev. Biophys. Biomol. Struct. 2006, 35, 225-249.

(4) Wang, Q.; Parrish, A. R.; Wang, L. Chem. Biol. 2009, 16, 323-336.

(5) Richmond, M. H. Bacteriol. Rev. 1962, 26, 398-420.

(6) Hecht, S. M.; Alford, B. L.; Kuroda, Y.; Kitano, S. J. Biol. Chem. 1978, 253, 4517-4520. of natural amino acids. ${ }^{7}$ An alternative, site-specific, approach based on suppressor tRNA allows incorporation of $u A A$ s during suppressor read-through of a stop codon, most often amber (UAG). ${ }^{8,9}$ This approach can be used in both in vitro protein translation systems and in in vivo translation systems that have been modified by the addition of an orthogonal tRNA-aminoacyl tRNA synthetase pair. ${ }^{10,11}$

This work describes the incorporation of $u A A$ s into a bacterial phosphotriesterase (arPTE) that has been cloned from an Agrobacterium radiobacter strain and catalyzes the hydrolysis of toxic organophosphate (OP) phosphotriester pesticides such as paraoxon. ${ }^{12}$ A $90 \%$ identical enzyme ( $p d$ PTE) has been isolated from Pseudomonas diminuta and Flavobacterium sp. strains and also exhibits OP degrading activity. ${ }^{13-15}$ These

(7) Hendrickson, W. A.; Horton, J. R.; LeMaster, D. M. EMBO J. 1990, 9, 1665-1672.

(8) Bain, J. D.; Diala, E. S.; Glabe, C. G.; Dix, T. A.; Chamberlin, A. R. J. Am. Chem. Soc. 1989, 111, 8013-8014.

(9) Noren, C. J.; Anthony-Cahill, S. J.; Griffith, M. C.; Schultz, P. G. Science 1989, 244, 182-188.

(10) Furter, R. Protein Sci. 1998, 7, 419-426.

(11) Wang, L.; Brock, A.; Herberich, B.; Schultz, P. G. Science 2001, 292, 498-500.

(12) Horne, I.; Sutherland, T. D.; Harcourt, R. L.; Russell, R. J.; Oakeshott, J. G. Appl. Environ. Microbiol. 2002, 68, 3371-3376.

(13) Mulbry, W. W.; Karns, J. S.; Kearney, P. C.; Nelson, J. O.; McDaniel, C. S.; Wild, J. R. Appl. Environ. Microbiol. 1986, 51, 926-930.

(14) Munnecke, D. M.; Hsieh, D. P. Appl. Microbiol. 1974, 28, 212-217. 
Scheme 1. Hydrolysis of Paraoxon at Basic pH Catalyzed by PTE<smiles>CCOP(=O)(OCC)Oc1ccc([N+](=O)[O-])cc1</smiles>

Scheme 2. Catalytic Cycle of PTEs

$$
E+S \underset{k_{2}}{\stackrel{k_{1}}{\rightleftarrows}} E S \stackrel{k_{3}}{\longrightarrow} E P Q \stackrel{k_{5}}{\longrightarrow} E+P+Q
$$

proteins are of interest because of their rapid evolution into efficient catalysts of the hydrolysis of synthetic OPs and their potential use for OP detoxification because these compounds pose a serious health and environmental risk. ${ }^{16}$

Many studies of the structure and function of the bacterial PTEs have been described, with crystal structures of arPTE and pdPTE revealing very close structural similarity (backbone rmsd of $0.34 \AA$ ) and nearly identical active sites with a binuclear metal ion center. ${ }^{17,18}$ Each metal ion plays a specific role in the reaction (Scheme 1), with the more solvent exposed $\beta$-metal ion apparently involved in substrate coordination and the $\alpha$-metal ion involved in stabilizing a hydroxide ion as the initiating nucleophile. ${ }^{19-23}$ Paraoxon is known to be hydrolyzed via an $\mathrm{S}_{\mathrm{N}}$ 2-type reaction with net inversion of configuration at the phosphorus center, ${ }^{24}$ and the rate of product release $\left(k_{5}\right)$ has been identified as the slowest and rate-limiting step of the catalytic cycle (Scheme 2)..$^{20,25-27}$

Discussion of the catalytic power of enzymes often focuses on the chemical step, ${ }^{28}$ but the subtle interactions that facilitate substrate binding and product release are also important; without fast rates for formation of the Michaelis complex and product release, the efficiency of the chemical step can be obscured. Because the chemical step is not rate-limiting for PTE-catalyzed paraoxon hydrolysis, the PTEs are a valuable model system to study these physical steps in the catalytic cycle. Although

(15) Serdar, C. M.; Gibson, D. T.; Munnecke, D. M.; Lancaster, J. H. Appl. Environ. Microbiol. 1982, 44, 246-249.

(16) Jaga, K.; Dharmani, C. Rev. Environ. Health 2006, 21, 57-67.

(17) Benning, M. M.; Kuo, J. M.; Raushel, F. M.; Holden, H. M. Biochemistry 1995, 34, 7973-7978.

(18) Yang, H.; Carr, P. D.; McLoughlin, S. Y.; Liu, J. W.; Horne, I.; Qiu, X.; Jeffries, C. M. J.; Russell, R. J.; Oakeshott, J. G.; Ollis, D. L. Protein Eng. 2003, 16, 241-241.

(19) Aubert, S. D.; Li, Y. C.; Raushel, F. M. Biochemistry 2004, 43, $5707-$ 5715.

(20) Hong, S. B.; Raushel, F. M. Biochemistry 1996, 35, 10904-10912.

(21) Jackson, C.; Kim, H. K.; Carr, P. D.; Liu, J. W.; Ollis, D. L. Biochim. Biophys. Acta 2005, 1752, 56-64.

(22) Jackson, C. J.; Foo, J. L.; Kim, H. K.; Carr, P. D.; Liu, J. W.; Salem, G.; Ollis, D. L. J. Mol. Biol. 2008, 375, 1189-1196.

(23) Foo, J. L.; Jackson, C. J.; Carr, P. D.; Kim, H. K.; Schenk, G.; Gahan, L. R.; Ollis, D. L. Biochem. J. 2010, 429, 313-321.

(24) Lewis, V. E.; Donarski, W. J.; Wild, J. R.; Raushel, F. M. Biochemistry 1988, 27, 1591-1597.

(25) Caldwell, S. R.; Newcomb, J. R.; Schlecht, K. A.; Raushel, F. M. Biochemistry 1991, 30, 7438-7444.

(26) Caldwell, S. R.; Raushel, F. M.; Weiss, P. M.; Cleland, W. W. Biochemistry 1991, 30, 7444-7450.

(27) Jackson, C. J.; Foo, J. L.; Tokuriki, N.; Afriat, L.; Carr, P. D.; Kim, H. K.; Schenk, G.; Tawfik, D. S.; Ollis, D. L. Proc. Natl. Acad. Sci. U.S.A. 2009, 106, 21631-21636.

(28) Warshel, A.; Sharma, P. K.; Kato, M.; Xiang, Y.; Liu, H. B.; Olsson, M. H. M. Chem. Rev. 2006, 106, 3210-3235.

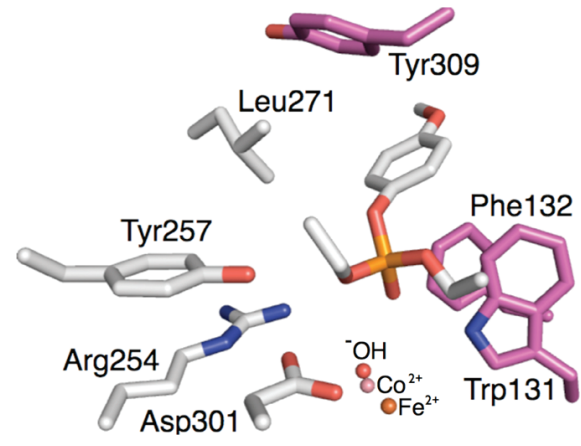

Figure 1. Aromatic interactions between Tyr309, diethyl-methoxyphenylphosphate, and Phe132 in the crystal structure of arPTE (PDB ID: 2R1N). Amino acid side chains forming face - face and edge - face aromatic stacking interactions with the aromatic group of the substrate are shown in magenta. The Fe(II) (orange), Co(II) (pink), and water/hydroxyl (red) molecules in the active site are shown as spheres.

substrate binding in the PTEs is driven in part by metal-substrate interactions, ${ }^{20}$ an important role for aromatic and hydrophobic enzyme-substrate (ES) interactions is implied by crystal structures of Michaelis and product complexes, which show the aromatic ring of the leaving group sandwiched between the aromatic groups of Tyr309, Trp131, and Phe132 (Figure 1). ${ }^{22,27}$ Moreover, mutation of these residues to alanine results in an increase in the Michaelis constant $\left(K_{\mathrm{M}}\right),{ }^{29,30}$ suggesting that these residues are involved in the formation of the Michaelis complex. However, theoretical studies have either indicated that the substrate approaches for nucleophilic attack without significant aromatic interactions with these residues, ${ }^{31,32}$ or have omitted these residues altogether. ${ }^{33}$

There have been several reports of protein engineering experiments to improve the catalytic function of the PTEs, involving rational design, ${ }^{29,30}$ combinatorial libraries, ${ }^{34,35}$ and laboratory (directed) evolution. ${ }^{18,27,36-38}$ Most of these studies have focused on improving inefficient, promiscuous, activities of the PTEs, such as the turnover of OPs used as chemical warfare agents or other slowly turned over insecticides. Attempts to improve already efficient activities, such as the turnover of paraoxon, have produced no, or only modest, improvements in arPTE in our laboratories, despite screening hundreds of thousands of variants. ${ }^{27,37}$ The inability to significantly improve the arPTE-mediated turnover of paraoxon by targeted and random mutagenesis suggests that there is likely to be little easily accessible sequence space available for improvement of this activity using naturally occurring $A A$ s.

In this study, we describe the incorporation of unnatural 7-methyl- and 7-hydroxycoumarinyl amino acids (Mco and Hco;

(29) Chen-Goodspeed, M.; Sogorb, M. A.; Wu, F.; Hong, S. B.; Raushel, F. M. Biochemistry 2001, 40, 1325-1331.

(30) Jackson, C. J.; Weir, K.; Herlt, A.; Khurana, J.; Sutherland, T. D.; Horne, I.; Easton, C.; Russell, R. J.; Scott, C.; Oakeshott, J. G. Appl. Environ. Microbiol. 2009, 75, 5153-5156.

(31) Koca, J.; Zhan, C. G.; Rittenhouse, R. C.; Ornstein, R. L. J. Am. Chem. Soc. 2001, 123, 817-826.

(32) Zhang, X.; Wu, R. B.; Song, L. C.; Lin, Y. C.; Lin, M. H.; Cao, Z. X.; Wu, W.; Mo, Y. R. J. Comput. Chem. 2009, 30, 2388-2401.

(33) Chen, S. L.; Fang, W. H.; Himo, F. J. Phys. Chem. B 2007, 111, $1253-$ 1255.

(34) Griffiths, A. D.; Tawfik, D. S. EMBO J. 2003, 22, 24-35.

(35) Hill, C. M.; Li, W. S.; Thoden, J. B.; Holden, H. M.; Raushel, F. M. J. Am. Chem. Soc. 2003, 125, 8990-8991.

(36) Cho, C. M.; Mulchandani, A.; Chen, W. Appl. Environ. Microbiol. 2004, 70, 4681-5.

(37) McLoughlin, S. Y.; Jackson, C.; Liu, J. W.; Ollis, D. Protein Expression Purif. 2005, 41, 433-440.

(38) Tokuriki, N.; Tawfik, D. S. Nature 2009, 459, 668-73. 


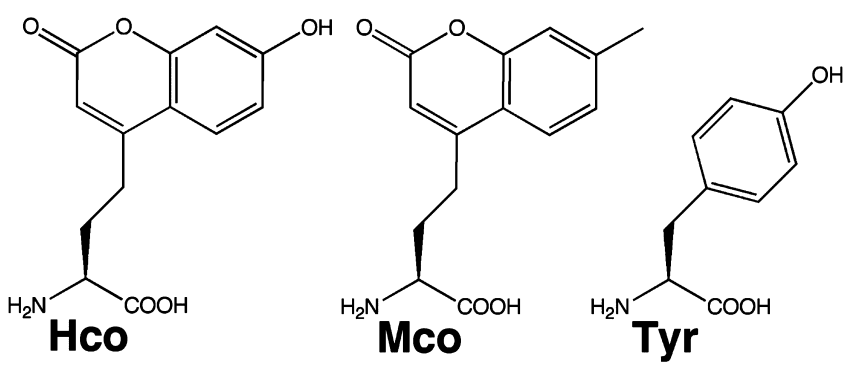

Figure 2. 7-Hydroxycoumarinyl (Hco), 7-methylcoumarinyl (Mco), and tyrosine (Tyr) amino acids incorporated at position 309.

Figure 2) in place of tyrosine 309 in the substrate binding site of arPTE through the use of coupled in vitro transcription/ translation of arPTE. These unnatural arPTE variants were constructed to probe the role of aromatic enzyme-substrate contacts in the catalytic cycle and to test whether $u A A s$ allow improvement of native catalytic efficiencies that have evolved with the 20 natural amino acids.

\section{Materials and Methods}

Materials, Reagents and Bacterial Strains. Paraoxon was purchased from Sigma Aldrich (USA). Molecular biology reagents and enzymes were purchased from Invitrogen (Australia), Finnzymes (Finland) or New England Biolabs (USA). Oligonucleotides for cloning of genes into expression vectors (Table 1 of the Supporting Information) were obtained from Geneworks (Australia). QIAGEN DNA purification kits were used for all DNA purifications unless stated otherwise. Calcium chloride competent $E$. coli cells from DH10 $\beta$ and BL21(DE3) strains, Luria broth (LB), LB agar, and antibiotics (ampicillin, chloramphenicol) were prepared as described by Sambrook et al. ${ }^{39}$ The vectors pSUP-CouRS-D8 and pSUPMjTyrRS-6TRN were a kind gift from Peter G. Schultz (The Scripps Research Institute, USA).

Preparation of $L$-(7-hydroxycoumarin-4-yl)ethylglycine (Hco). The compound was prepared using a modified version of the published method. ${ }^{40} \mathrm{Z}-\mathrm{Glu}-\mathrm{OBzl}$ was purchased from Bachem and all other reagents from Aldrich or Ajax Chemicals (Sydney, Australia). A solution of potassium hydroxide ( $16.8 \mathrm{~g}, 0.3 \mathrm{~mol})$ in $20 \mathrm{~mL}$ water was added slowly to an ice-cooled solution of ethyl hydrogen malonate $(39.7 \mathrm{~g}, 0.3 \mathrm{~mol})$ in $20 \mathrm{~mL}$ water. Magnesium chloride hexahydrate $(30.5 \mathrm{~g}, 0.15 \mathrm{~mol})$ was then added and the volume adjusted to $100 \mathrm{~mL}$ with water. $500 \mathrm{~mL}$ of isopropanol was added to precipitate potassium chloride and after $1 \mathrm{~h}$, the mixture was filtered. The filtrate was rotary evaporated (40 mbar, bath $40{ }^{\circ} \mathrm{C}$ ) to give $46.3 \mathrm{~g}$ of ethyl magnesium malonate as a white solid in quantitative yield. Carbonyldiimidazole ( $2.5 \mathrm{~g}, 15.1 \mathrm{mmol})$ was added under nitrogen in portions to a solution of Z-Glu-OBzl $(5.1 \mathrm{~g}, 13.7 \mathrm{mmol})$ in dry tetrahydrofuran $(50 \mathrm{~mL})$ at room temperature. After 75 min, ethyl magnesium malonate (4.3 g, 15.1 mmol) was added and the reaction mixture was stirred for $18 \mathrm{~h}$ during which a slow evolution of carbon dioxide occurred. 100 $\mathrm{mL}$ of water was added followed by $5 \mathrm{~mL}$ of $36 \% \mathrm{HCl}$ to adjust the $\mathrm{pH}$ to 3 . A white gummy solid separated. The mixture was extracted with three separate portions of $200 \mathrm{~mL}$ diethyl ether and the combined organic extracts washed with $100 \mathrm{~mL}$ each of $10 \%$ aqueous sodium bicarbonate, water, and saturated brine. After drying over sodium sulfate, filtering, and rotary evaporating, the white solid $(5.8 \mathrm{~g})$ was flash chromatographed with 1:1 ethyl acetate-hexane on a $220 \mathrm{~mm} \times 50 \mathrm{~mm}$ column of $40-63 \mu \mathrm{m}$ silica to yield the $\beta$-ketoester as a white solid (5.47 g, 90\%).

(39) Sambrook, J., Fritsch, E. F. Maniatis, T. Molecular Cloning: A Laboratory Manual; Cold Spring Harbor Laboratory Press: Cold Spring Harbor, N.Y., 1989.

(40) Wang, J. Y.; Xie, J. M.; Schultz, P. G. J. Am. Chem. Soc. 2006, 128, $8738-8739$.
The $\beta$-ketoester $(5.3 \mathrm{~g}, 12 \mathrm{mmol})$ was added slowly to a solution of resorcinol $(6.6 \mathrm{~g}, 60 \mathrm{mmol})$ in methanesulfonic acid $(48 \mathrm{~mL})$ at room temperature. After stirring for $1 \mathrm{~h}, 310 \mathrm{~mL}$ of diethyl ether was added and the mixture cooled to $-35{ }^{\circ} \mathrm{C}$. The mixture was stirred for 90 min to give a yellow precipitate, which was filtered off. The residue was dissolved in $100 \mathrm{~mL}$ of water and lyophilized overnight. It was then dissolved in $100 \mathrm{~mL}$ of water at $\mathrm{pH} 1.3$ and $1 \mathrm{M} \mathrm{NaOH}$ solution added until the $\mathrm{pH}$ of the mixture was 3.5 when a pink solid separates. The mixture was cooled in ice for $1 \mathrm{~h}$, filtered and the residue washed with three portions of ice-water at $\mathrm{pH} 3$ followed by three portions of acetone to give $1.9 \mathrm{~g}$ of crude $L$-(7-hydroxycoumarin-4-yl)ethylglycine as the zwitterions, HPLC purity approximately $90 \%$. The amino acid was further purified by dissolving in $50 \mathrm{~mL}$ of water adjusted to $\mathrm{pH} 1$ with methanesulfonic acid. Aliquots $(4.2 \mathrm{~mL})$ were injected onto a Waters Symmetry $(7$ $\mu \mathrm{m}, \mathrm{C} 18150 \mathrm{~mm} \times 19 \mathrm{~mm})$ semipreparative HPLC column and eluted at $8.5 \mathrm{~mL} / \mathrm{min}$ with 1:9 acetonitrile-water containing $0.1 \%$ trifluoroacetic acid for $15 \mathrm{~min}$ followed by a $10 \mathrm{~min}$ wash with $100 \%$ acetonitrile. Fractions containing the trifluoroacetate salt of the amino acid were pooled and rotary evaporated (12 mbar, bath $40{ }^{\circ} \mathrm{C}$ ). The residue was dissolved in $15 \mathrm{~mL} 1 \mathrm{M}$ sodium hydroxide at $0{ }^{\circ} \mathrm{C}$ and $36 \% \mathrm{HCl}$ added to adjust the $\mathrm{pH}$ to 3.5. The white solid was filtered off, washed three times with ice-water at $\mathrm{pH}$ 3.5 , and dried under high vacuum for $60 \mathrm{~h}$ at room temperature. The yield of the target compound as the zwitterion was $1.2 \mathrm{~g} \mathrm{(38 \% ),}$ HPLC purity $99 \%$. HPLC analysis was performed with a Waters Symmetry $(5 \mu \mathrm{m} \mathrm{C18} 150 \mathrm{~mm} \times 4.6 \mathrm{~mm})$ HPLC column, eluted at $1 \mathrm{~mL} / \mathrm{min}$ with a 20 min linear gradient from 10 to $100 \%$ acetonitrile in water containing $0.1 \%$ trifluoracetic acid, and monitoring at $323 \mathrm{~nm}$. At $22{ }^{\circ} \mathrm{C}$, the compound eluted at $7.0 \mathrm{~min}$. Stock solutions $(50 \mathrm{mM})$ of $\mathrm{Hco}$ in $100 \mathrm{mM} \mathrm{KOH}$ were made and $1 \mathrm{~mL}$ aliquots stored at $-80{ }^{\circ} \mathrm{C}$ until needed.

Preparation of $\boldsymbol{L}$-(7-methylcoumarin-4-yl)ethylglycine (Mco). Synthesis of $L$-(7-methylcoumarin-4-yl)ethylglycine hydrochloride (Mco) was performed as follows. The $\beta$-ketoester derived from Z-Glu-OBzl (3.25 g, 7.4 mmol), prepared as previously described ${ }^{40}$ was added in portions to a $4 \mathrm{~mL}$ stirred solution of $37 \mathrm{mmol}$ $m$-cresol in $30 \mathrm{~mL}$ of methanesulfonic acid at room temperature. After $3.5 \mathrm{~h}$, the deep yellow reaction mixture was poured into 90 $\mathrm{mL}$ of ice water and extracted twice with $100 \mathrm{~mL}$ of diethyl ether. The $\mathrm{pH}$ was adjusted to 4.6 with sodium hydroxide (18.5 g in 30 $\mathrm{mL}$ water) followed by $1 \mathrm{M}$ sodium hydroxide. A small amount of a pink oily solid was filtered off and the volume of the filtrate was reduced to approximately $120 \mathrm{~mL}$ using a rotary evaporator (condenser $-10{ }^{\circ} \mathrm{C}$, bath $40{ }^{\circ} \mathrm{C}$ ) and the product was allowed to stand for 3 days. The white solid that separated was filtered off, washed with ice water, and dried in air. This material $(325 \mathrm{mg}$ ) was slurried with water and $1 \mathrm{M} \mathrm{HCl}$ added until it fully dissolved (total volume approximately $15 \mathrm{~mL}$ ). The acidified solution was extracted with two half volumes of distilled dichloromethane. The aqueous phase was then rotary evaporated (condenser $-10^{\circ} \mathrm{C}$, bath $30{ }^{\circ} \mathrm{C}$ ) to remove traces of organic solvent and lyophilized to give $353 \mathrm{mg}$ of 4-(7-methylcoumarinyl)-2-ethylglycine hydrochloride as a cream colored solid in $16 \%$ yield. Stock solutions $(50 \mathrm{mM})$ of Mco in $100 \mathrm{mM} \mathrm{KOH}$ were made and $1 \mathrm{~mL}$ aliquots stored at $-80{ }^{\circ} \mathrm{C}$ until needed.

Mutagenesis and Cloning. A Tyr309amber (TAG) mutant was produced by overlapping PCR with primers PTE_MF, PTE_MR, PTE-Y309TAG_F, and PTE-Y309TAG_R (Table 1 of the Supporting Information) using the opdA gene (encoding arPTE) as a template. Tyr309Leu, Tyr309Phe, and Tyr309Trp mutants were similarly generated from the opdA gene using the primers PTE_MF, PTE_MR, PTE-Y309L_F, PTE-Y309L_R, PTE-Y309F_F, PTEY309F_R, PTE-Y309W_F, and PTE-Y309W_R (Table 1 of the Supporting Information). The PCR products were digested and ligated into pETMCSI vector ${ }^{41}$ between the NdeI and EcoRI restriction sites. The resulting construct was verified by DNA sequencing. 
Expression of Wild-Type arPTE and Variants. Wild-type arPTE (Tyr309) and Tyr309Leu, Tyr309Phe, Tyr309Trp, Tyr309Hco, and Tyr309Mco variants were expressed in vitro using a cell-free protein synthesis system with natural and unnatural amino acids, as has been described previously. ${ }^{42}$ The only difference was that the $\operatorname{arPTE}$ variants were expressed overnight at $30{ }^{\circ} \mathrm{C}$ and no components for unnatural amino acid incorporation were included for the expression of wild-type or natural arPTE variants. The methods for expression and purification of $L$-(7-hydroxycoumarin4-yl) ethylglycine (Hco) tRNA synthetase (CouRS) and expression and purification of total tRNA including an amber suppressor tRNA (Sup-tRNA) have been previously described. ${ }^{42}$ The soluble protein fraction was loaded on to a DEAE Fractogel column (Merck Biosciences, Australia), to which arPTE and variants did not bind and was collected in the flow-through. The protein was then dialyzed overnight against $20 \mathrm{mM}$ HEPES, $\mathrm{pH} 7.0$, and loaded onto a $1 \mathrm{~mL}$ resource $\mathrm{S}$ column (GE Healthcare, UK). Bound arPTE was eluted at approximately $150 \mathrm{mM} \mathrm{NaCl}$ using a linear gradient from 0 to $1 \mathrm{M}$. SDS-PAGE analysis of the eluted arPTE protein indicated a purity of greater than $95 \%$. Protein concentrations were determined by measuring absorbance at $280 \mathrm{~nm}$ using an extinction coefficient $(\varepsilon)$ of $29280 \mathrm{M}^{-1} \mathrm{~cm}^{-1}$ for wild-type, $29410 \mathrm{M}^{-1} \mathrm{~cm}^{-1}$ for Tyr309Hco and Tyr309Mco, $28130 \mathrm{M}^{-1} \mathrm{~cm}^{-1}$ for Tyr309Leu and Tyr309Phe, and $33820 \mathrm{M}^{-1} \mathrm{~cm}^{-1}$ for Tyr309Trp. Relative concentrations were confirmed using SDS-PAGE.

Wild-type arPTE was also expressed in E. coli BL21(DE3) cells by autoinduction in terrific broth (TB) medium. ${ }^{43}$ The activity of this preparation was essentially identical to that of the in vitro expressed sample $\left(k_{\text {cat }} / K_{\mathrm{M}}\right.$ (in vivo) $=2.56 \times 10^{7} \mathrm{~s}^{-1} \mathrm{M}^{-1}$ versus $k_{\text {cat }} / K_{\mathrm{M}}$ (in vitro) $=2.70 \times 10^{7} \mathrm{~s}^{-1} \mathrm{M}^{-1} ;$ Figure 1 of the Supporting Information). Cells were harvested by centrifugation and resuspended in $20 \mathrm{mM}$ Tris- $\mathrm{HCl}$ buffer, $\mathrm{pH} 8.0$ before being lysed using a French pressure cell (Thermo, USA) at $4{ }^{\circ} \mathrm{C}$ and cell debris was removed by centrifugation at $30000 \times g$ for $30 \mathrm{~min}$. Purification was performed as described above. ${ }^{44}$

Confirmation of Insertion of Hco and Mco by In-Gel Tryptic Digest LC/MS. The incorporation of Hco and Mco into arPTE was verified by LC/MS using previously described methodology. ${ }^{45}$ Protein samples were separated by SDS-PAGE and visualized by staining with Coomassie blue. Protein bands that migrated at the correct size $(\sim 36 \mathrm{kDa})$ were excised from the gel, diced into $1 \mathrm{~mm}$ cubes, transferred to a clean $0.5 \mathrm{~mL}$ Eppendorf tube and washed with a mixture of $150 \mu \mathrm{L} 25 \mathrm{mM}$ ammonium bicarbonate and $10 \mu \mathrm{L} 45 \mathrm{mM}$ dithiothreitol (DTT) on a heating block set at $60{ }^{\circ} \mathrm{C}$ for $30 \mathrm{~min}$. The wash was discarded and gel pieces subsequently washed three times with $50 \mu \mathrm{L}$ of $1: 1$ mixture of acetonitrile $(\mathrm{ACN})$ and $25 \mathrm{mM}$ ammonium bicarbonate for 20 min each. The gel pieces were further washed three times for 20 min each with $100 \% \mathrm{ACN}$ and subsequently dried under vacuum to remove traces of ACN. Rehydration of gel pieces was accomplished with $8 \mu \mathrm{L}$ of protease solution $(3 \mu \mathrm{L}$ of Promega (Australia) sequencing grade trypsin in $100 \mu \mathrm{L}$ ammonium bicarbonate solution) followed by incubation on a $37^{\circ} \mathrm{C}$ heating block for $4 \mathrm{~h}$. The set up was transferred to a $37{ }^{\circ} \mathrm{C}$ water bath and left to stand overnight. The condensed fluid under the lid of the microfuge tube was discarded and the gels were rehydrated with $10 \mu \mathrm{L}$ of $0.1 \%$ formic acid and left to stand on the bench for 30 min. The solution containing peptides that diffused from the gel

(41) Neylon, C.; Brown, S. E.; Kralicek, A. V.; Miles, C. S.; Love, C. A.; Dixon, N. E. Biochemistry 2000, 39, 11989-11999.

(42) Ugwumba, I. N., Ozawa, K., de la Cruz, L., Xu, Z., Herlt, T., Hadler, K. S. Coppin, C., Brown, S. E., Schenk, G., Oakeshott, J. G. Otting, G. Assay Drug Dev. Technol. 2010, epub ahead of print: doi:10.1089/ adt.2010.0306.

(43) Studier, F. W. Protein Expression Purif. 2005, 41, 207-234.

(44) Jackson, C. J.; Carr, P. D.; Kim, H. K.; Liu, J. W.; Herrald, P.; Mitic, N.; Schenk, G.; Smith, C. A.; Ollis, D. L. Biochem. J. 2006, 397, 501-508.

(45) Campbell, P. M.; Cao, A. T.; Hines, E. R.; East, P. D.; Gordon, K. H. J. Insect Biochem. Mol. Biol. 2008, 38, 950-958. pieces was pipetted into a 96-well microplate and analyzed by LCESI- Ion Trap Mass Spectroscopy/Mass Spectroscopy (LC-MS/MS) using an Agilent 1100 capillary liquid chromatography system with an Agilent XCT ion trap mass spectrometer. Mass spectral data sets were analyzed by matching with sequence databases using Agilent's Spectrum Mill software (Agilent Technologies, USA) to generate a peptide map. False positive matches were avoided by using the software's stringent autovalidation default settings. Mass search for Hco- and Mco-containing peptides was performed by matching the calculated $+1,+2,+3$, and +4 charged peptide masses generated using the Protein Prospector tool (University of California, SF, USA) with those identified from the spectral data.

Modeling of the Tyr309Hco Variant. The possible conformations of the Hco side chain in the Hco309 variant were examined manually using the program COOT. ${ }^{46}$ The molecular topology of Hco was generated using the PRODRG server, ${ }^{47}$ as were restraints for bond angles and lengths. The main chain atoms were superimposed with those of Tyr309 in the $2 \mathrm{R}^{2} \mathrm{~N}^{22}$ structure of the enzyme-substrate complex and the side chain was rotated to examine possible stable rotamers in which the Hco residue was not involved in steric clashes with either the substrate or other amino acid side chains.

Detection of Diethyl Phosphate and 4-Nitrophenol by Mass Spectrometry. To establish that diethyl phosphate and 4-nitrophenol were both released from the enzyme as a result of the hydrolysis of paraoxon by Tyr309Hco arPTE (Hco309), a reaction mixture containing $10 \mathrm{mM}$ paraoxon in $50 \mathrm{mM}$ Tris- $\mathrm{HCl}$, $\mathrm{pH} 8.50,20 \%$ methanol, and $0.2 \mathrm{nM} \mathrm{Hco309}$ was allowed to stand for $5 \mathrm{~min}$. A control sample was similarly set up but with an enzyme solution that had been inactivated by heating at $70{ }^{\circ} \mathrm{C}$ for $30 \mathrm{~min}$ on a heating block. Standard solutions containing $2 \mathrm{mM}$ pure samples of diethyl phosphate and 4-nitrophenol (Sigma Aldrich, USA) were also prepared in the same buffer. The samples were analyzed by negative mode LC/MS ESI ToF using an Agilent 1100 capillary liquid chromatography system with an Agilent MSD ToF mass spectrometer (Agilent Technologies, USA). The column used was an Agilent Zorbax Eclipse XDB-C18 (inner dimensions 3.5 $\mu \mathrm{m} \times 30 \mathrm{~mm}$ ) rapid resolution column (Agilent Technologies, USA). Ten microliters of each sample was injected and separation was achieved using a gradient $(0-90 \%)$ of acetonitrile with $0.1 \%$ formic acid with a flow rate of $0.8 \mathrm{~mL} / \mathrm{min}$ for $5 \mathrm{~min}$. Analysis of mass spectral data to identify diethyl phosphate and 4-nitrophenol was performed using Analysts QS software (Agilent Technologies, USA).

Enzyme Kinetics and pH-Rate Profiles. Kinetic measurements of the catalyzed hydrolysis of paraoxon were performed according to published procedures. ${ }^{19}$ The catalytic activity of the variants of arPTE was assayed by measuring the release of 4-nitrophenol/4nitrophenolate spectrophotometrically at $347 \mathrm{~nm}\left(\varepsilon_{347}=5176\right.$ $\mathrm{M}^{-1} \mathrm{~cm}^{-1}$ ), the isosbestic wavelength for the substituted phenol and corresponding phenolate. The $\mathrm{pH}$-dependence of the phosphotriesterase activity of arPTE was analyzed using $10-1000 \mu \mathrm{M}$ paraoxon as the substrate over $\mathrm{pH} 4.0-10.0$ in $0.5 \mathrm{pH}$ unit increments. Reactions were conducted in a multicomponent buffer (MCB) composed of $50 \mathrm{mM}$ each of acetate, MES, HEPES, CHES, and CAPS, to maintain the same ionic strength in the $\mathrm{pH}$ buffering range. ${ }^{48}$ Activity measurements were performed in a 96 well microplate at $30{ }^{\circ} \mathrm{C}$ using a BMG Polarstar SPECTRAmax M2 microplate reader (Molecular Devices). A $4 \times$ arPTE enzyme solution was prepared in $2 \mathrm{mM}$ Tris- $\mathrm{HCl}, \mathrm{pH} 8.0$, containing 0.5 $\mathrm{mg} / \mathrm{mL}$ bovine serum albumin (BSA). The final $300 \mu \mathrm{L}$ reaction mixture contained $75 \mu \mathrm{L}$ of $4 \times$ arPTE enzyme solution, $75 \mu \mathrm{L}$ of $4 \times \mathrm{MCB}$ solution, and $150 \mu \mathrm{L}$ of $2 \times$ substrate solution. All assays were conducted in duplicate and in $20 \%$ methanol, because of the

(46) Emsley, P.; Lohkamp, B.; Scott, W. G.; Cowtan, K. Acta Crystallogr. Sect. D: Biol. Crystallogr. , 66, 486-501.

(47) Schuttelkopf, A. W.; van Aalten, D. M. Acta Crystallogr. Sect. D: Biol. Crystallogr. 2004, 60, 1355-1363.

(48) Ellis, K. J.; Morrison, J. F. Methods Enzymol. 1982, 87, 405-426. 
limited solubility of the substrate. The kinetic parameters, $k_{\mathrm{cat}}$ and $k_{\text {cat }} / K_{\mathrm{M}}$, were obtained by fitting the data to the Michaelis-Menten equation using the curve fitting software, GraphPad Prism (GraphPad Software Inc., USA). The values of $k_{\text {cat }}$ and $k_{\text {cat }} / K_{\mathrm{M}}$ were determined by fitting the initial velocity data to the equation

$$
v=V_{\max }[S] /\left(K_{\mathrm{M}}+[S]\right)
$$

where $v$ is the initial velocity, $V_{\max }$ is the maximum velocity, $S$ is the substrate concentration, and $K_{\mathrm{M}}$ is the Michaelis constant. In the case of an enzyme for which product dissociation $\left(k_{5}\right)$ is ratelimiting, $K_{\mathrm{M}}$ is defined by eq 2 , where $k_{1}, k_{2}, k_{3}$, and $k_{5}$ are shown in Scheme 2.

$$
K_{\mathrm{M}}=\left(k_{5}\left(k_{2}+k_{3}\right)\right) /\left(k_{1}\left(k_{3}+k_{5}\right)\right)
$$

$\mathrm{p} K_{\mathrm{a}}$ values were determined from $\mathrm{pH}$-rate profiles by fitting the experimental data to eqs 3 or 4 for single-proton and double-proton profiles, respectively,

$$
\begin{gathered}
\log y=\log \left(\frac{c}{1+\frac{[\mathrm{H}]}{K_{1}}}\right) \\
\log y=\log \left(\frac{c\left(1+\frac{a K_{2}}{[\mathrm{H}]}\right)}{1+\frac{[\mathrm{H}]}{K_{1}}+\frac{K_{2}}{[\mathrm{H}]}}\right)
\end{gathered}
$$

where $[\mathrm{H}]$ is the proton concentration, $K_{1}$ and $K_{2}$ represent protonation equilibria, $c$ and $a$ are the $\mathrm{pH}$ independent values of $y$, and $y$ is the kinetic parameter which can be either $k_{\text {cat }}$ or $k_{\text {cat }} / K_{\mathrm{M}}$.

\section{Results and Discussion}

In Vitro Protein Expression and Incorporation of Unnatural Amino Acids in arPTE. To probe the role of aromatic interactions in ES and EP complexes of arPTE, two unnatural variants were created: Tyr309Hco and Tyr309Mco (Figure 2). These unnatural coumarinyl amino acids were chosen so that the variants would retain aromatic character in this region of the protein structure, whereas the hydroxyl group of Hco can be titrated through a $\mathrm{pH}$ region of high catalytic activity for arPTE ( $\mathrm{pH} \mathrm{8-9),} \mathrm{allowing} \mathrm{the} \mathrm{effect} \mathrm{of} \mathrm{its} \mathrm{protonation} \mathrm{state}$ on activity to be monitored. Mco provided a control, being completely analogous to Hco with the exception that the ionizable hydroxyl group is replaced with a methyl group. The codon for Tyr309 in the wild-type gene encoding arPTE was mutated to the amber (TAG) stop codon, to be used in conjunction with mutant suppressor tRNA, $M j \operatorname{tRNA}^{\mathrm{Tyr}}{ }_{\mathrm{CUA}}$, which was enzymatically acylated with either Mco or Hco by purified engineered tRNA synthetase CouRS. ${ }^{40}$ The translational incorporation of this residue was carried out using a cell-free coupled transcription/translation system that allowed the various nucleic acid, protein, and chemical components required for synthesis of the gene to be added in defined quantities, ${ }^{49}$ allowing optimization of the conditions for maximal protein yield using a minimum quantity of $u A A s$; an important consideration given that they are not commercially available and required synthesis. Wild-type arPTE was produced in higher yield in vitro than Tyr309Hco, which was in turn produced in higher yield than Tyr309Mco (47 $\mu \mathrm{g}$ vs $13 \mu \mathrm{g}$ vs $4 \mu \mathrm{g}$ per mL of cell-free reaction mixture). This was expected considering

(49) Ozawa, K.; Headlam, M. J.; Schaeffer, P. M.; Henderson, B. R.; Dixon, N. E.; Otting, G. Eur. J. Biochem. 2004, 271, 4084-4093.

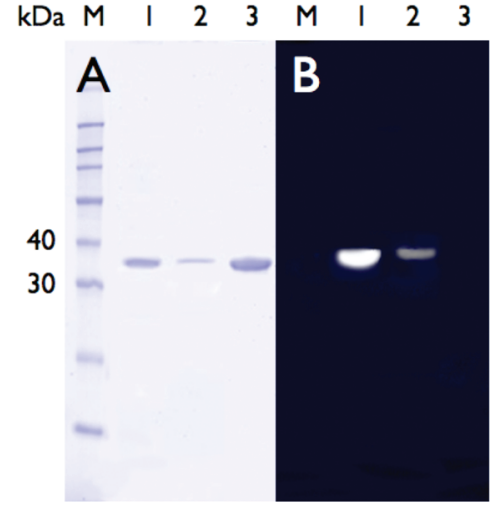

Figure 3. SDS-PAGE analysis of wild-type and variant arPTEs: (A) gel stained with Coomassie blue, (B) same gel observed by fluorescence $\left(\mathrm{Ex}_{\lambda}\right.$ $=360 \mathrm{~nm}$ and $\mathrm{Em}_{\lambda}=460 \mathrm{~nm}$ ); Lane $M=$ molecular weight marker, $1=$ Tyr309Hco, 2 = Tyr309Mco, 3 = wild type $\operatorname{arPTE}$.

that wild-type expression used naturally evolved tRNA synthetases, while the incorporation of Hco and Mco relied on a tRNA synthetase, CouRS, that was engineered to accommodate Hco. $^{40}$

SDS-PAGE was used to confirm that Hco and Mco were incorporated into arPTE (Figure 3). Before staining with Coomassie blue, the gel was imaged by fluorescence with excitation and detection wavelengths of 360 and $460 \mathrm{~nm}$, which are near the excitation $(367 \mathrm{~nm})$ and emission $(455 \mathrm{~nm})$ maxima of 7-hydroxycoumarin. The full-length Hco- and Mco-containing proteins, which behaved identically to wild-type arPTE under Coomassie staining, were clearly fluorescent, consistent with incorporation of the $u A A s$. The Hco-containing protein band had much higher fluorescence than the Mco protein band, consistent with the 260-fold higher fluorescence of free Hco in solution compared with Mco at these wavelengths (Figure 2 of the Supporting Information). Further confirmation for the sitespecific incorporation of Hco and Mco was obtained through tryptic peptide mass fingerprinting (Figure 4), which identified peptides from segments of protein both before and after residue 309, indicating the expression of full-length Tyr309Hco and Tyr309Mco proteins. The coumarinyl-glycine-containing peptides (ILVSHDWLFGFSSHcoVTNIMDVMD and ILVSHDWLFGFSSMcoVTNIMDVMD) were identified by peptic ion masses. The matched peptides covered $44 \%$ of the protein, including the predicted $\mathrm{N}$ and $\mathrm{C}$ termini.

Mechanistic Analysis of Unnatural Phosphotriesterases. The effects of the Tyr309Hco and Tyr309Mco mutations on the catalytic behavior of arPTE were examined using $\mathrm{pH}$-rate profiles. Figure 5 shows $\mathrm{pH}$-rate profiles for the catalyzed hydrolysis of paraoxon by wild-type arPTE and the unnatural variants over a $\mathrm{pH}$ range of $4.0-10.0$ (Table 1 ). All variants exhibit acidic dissociation constants with $\mathrm{p} K_{\mathrm{e}}$ and $\mathrm{p} K_{\mathrm{es}}$ values between 4.0 and 5.0, consistent with previous results for native wild-type arPTE, ${ }^{21}$ which indicates a titration of the rate-limiting step from catalysis $\left(k_{3}\right)$ to a physical step (product release, $k_{5}$ ), as described previously. ${ }^{19}$ However, unlike wild-type and Tyr309Mco arPTE, the Tyr309Hco variant undergoes a second deprotonation event at basic $\mathrm{pH}$. We note that the effect of this is less significant than the acidic protonation event, as seen in the lower slope of this curve (ca. 0.2 vs 0.6 ). The $\mathrm{p} K_{\mathrm{a}}$ value of this deprotonation event $(8.2-8.4)$ corresponds to the $\mathrm{p} K_{\mathrm{a}}$ of the hydroxyl group of the 7-hydroxycoumarinyl side chain 

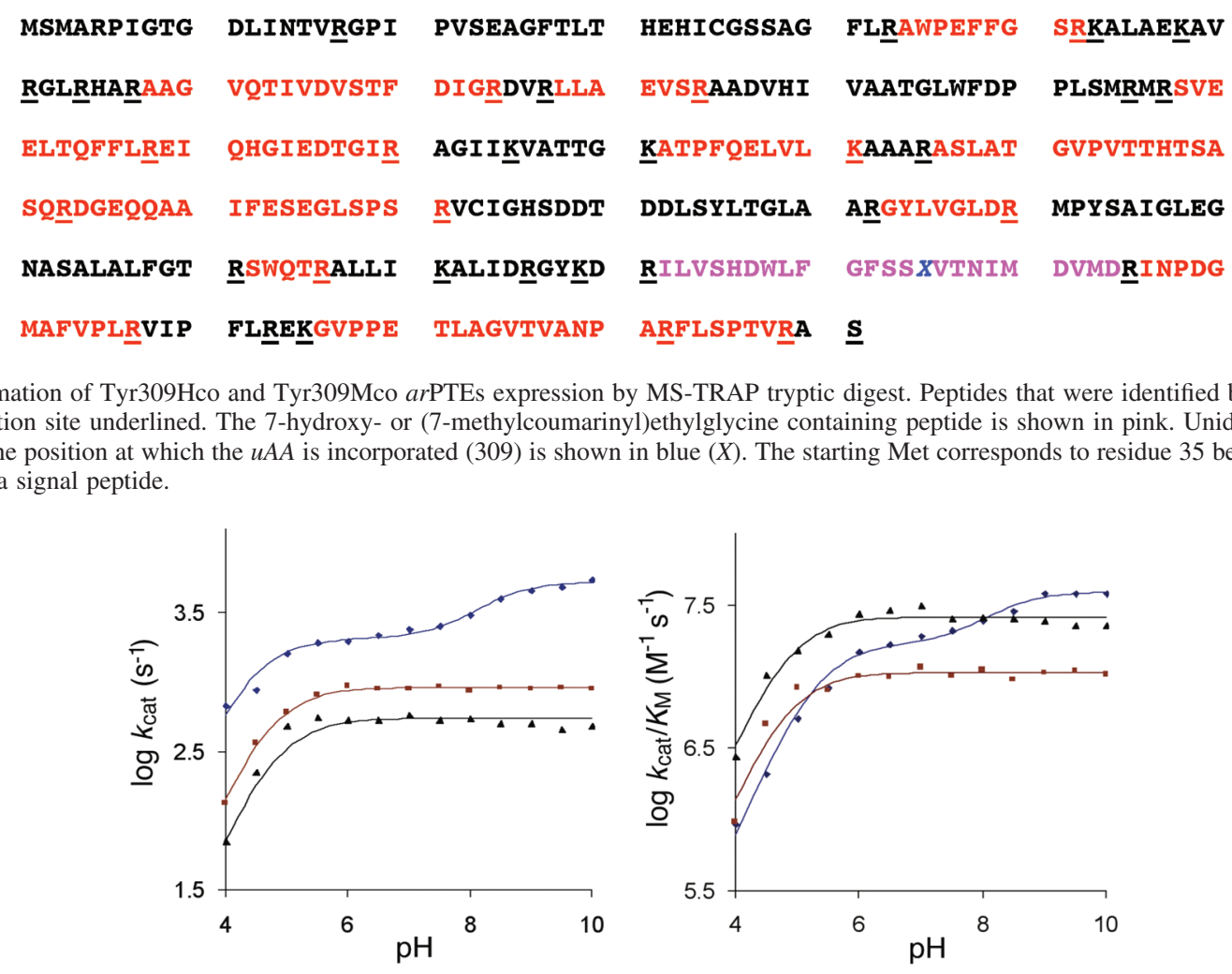

Figure 4. Confirmation of Tyr309Hco and Tyr309Mco arPTEs expression by MS-TRAP tryptic digest. Peptides that were identified by MS are shown in red with the digestion site underlined. The 7-hydroxy- or (7-methylcoumarinyl)ethylglycine containing peptide is shown in pink. Unidentified sequence is shown in black. The position at which the $u A A$ is incorporated (309) is shown in blue $(X)$. The starting Met corresponds to residue 35 because the expressed protein is lacking a signal peptide.

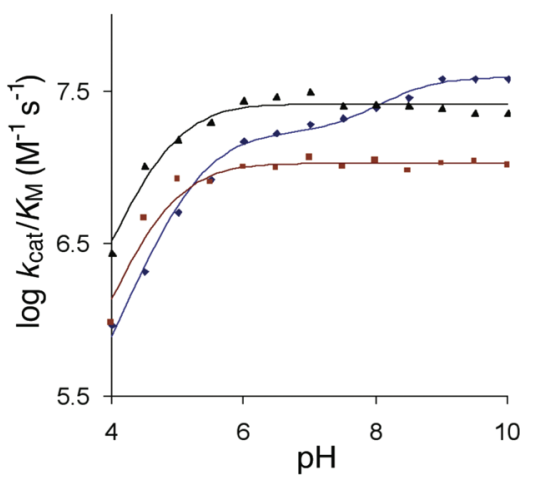

Figure 5. $\mathrm{pH}-$-dependence of the catalytic rate constants for wild-type (black), Tyr309Mco (red), and Tyr309Hco (blue) variants of arPTE for the hydrolysis of paraoxon at room temperature.

Table 1. Acid Dissociation Constants for Wild-Type arPTE and the Unnatural Variants Mco309 and Hco309

\begin{tabular}{ccl}
\hline variant & $\mathrm{pK} K_{\mathrm{e}, 2}$ & $\mathrm{pK} K_{\mathrm{es}, 2,}$ \\
\hline Tyr309 & $4.7,-$ & $4.8,-$ \\
$\mathrm{M} \operatorname{co3} 09$ & $4.7,-$ & $4.8,-$ \\
$\mathrm{H} \operatorname{co309}$ & $4.7,8.4$ & $5.2,8.2$ \\
\hline
\end{tabular}

(8.3), ${ }^{50}$ suggesting that the change in the protonation state of this hydroxyl moiety causes the change in activity across $\mathrm{pH}$ $8-9$. This conclusion is also supported by the observation that the turnover rate of the Mco309 variant does not change over the same $\mathrm{pH}$ range and Mco is structurally identical to Hco with the exception that the hydroxyl group is replaced by a methyl group.

In addition to Hco and Mco, we made three other natural variants of arPTE at this position: Leu309, Phe309, and Trp309. Kinetic parameters for the six variants at $\mathrm{pH} 8.5$ are reported in Table 2. For efficient turnover, an enzyme must balance strong interactions with the substrate $\left(k_{1}[S] \gg k_{2}\right)$ with fast dissociation of products $\left(k_{5}\right)$, around an efficient chemical step $\left(k_{3}\right)$. Because of the similarity between substrate and product in many reactions, this is not always an easy feat. The data in Table 2 show that improvement in substrate turnover for enzymes such as arPTE, where the chemical step is not rate limiting, depends upon mutations differentially affecting substrate binding and product release. In the case of the PTEs, it is difficult to assess the effects of mutations by analyzing $K_{\mathrm{M}}$ because it is a combination of $k_{1}, k_{2}, k_{3}$, and $k_{5}$ (eq 2). However, the relative changes of $k_{\text {cat }}$ and $K_{\mathrm{M}}$ in the variants clearly show that different mutations affect the various microscopic constants

(50) Ferrari, A. M.; Sgobba, M.; Gamberini, M. C.; Rastelli, G. Eur. J. Med. Chem. 2007, 42, 1028-1031.
Table 2. Kinetic Parameters for the Hydrolysis of Paraoxon at $\mathrm{pH}$ 8.5 by arPTE Variants with Natural and Unnatural Mutations at Position 309; the Wild-Type Residue is Tyr

\begin{tabular}{llll}
\hline variant & \multicolumn{1}{c}{$k_{\text {cat }}$} & \multicolumn{1}{c}{$k_{\mathrm{M}}$} & \multicolumn{1}{c}{$k_{\text {cat }} / K_{\mathrm{M}}$} \\
\hline & $\mathrm{s}^{-1}$ & $\mu \mathrm{M}$ & $\mathrm{s}^{-1} \mathrm{M}^{-1}$ \\
Tyr309 & $510 \pm 10$ & $20 \pm 1$ & $2.5 \times 10^{7}$ \\
Leu309 & $260 \pm 9$ & $51 \pm 4$ & $5.1 \times 10^{6}$ \\
Phe309 & $465 \pm 13$ & $73 \pm 6$ & $6.4 \times 10^{6}$ \\
Trp309 & $436 \pm 11$ & $80 \pm 7$ & $5.5 \times 10^{6}$ \\
Mco309 & $910 \pm 20$ & $96 \pm 7$ & $9.4 \times 10^{6}$ \\
Hco309 & $3990 \pm 110$ & $138 \pm 8$ & $2.9 \times 10^{7}$ \\
\hline
\end{tabular}

differently. The comparison between wild-type, Tyr309Mco, and Tyr309Hco is particularly informative: for Tyr309Mco we see $K_{\mathrm{M}}$ increase much more than $k_{\text {cat }}$, whereas for Tyr309Hco $K_{\mathrm{M}}$ and $k_{\text {cat }}$ increase similarly. Thus, for Tyr309Hco the concerted increase in $K_{\mathrm{M}}$ and $k_{\text {cat }}$ can be largely attributed to an increase in $k_{5}$. In contrast, for Tyr309Mco, the much larger increase in $K_{\mathrm{M}}$ than in $k_{\text {cat }}$ suggests that the affinity between enzyme and substrate $\left(k_{1}\right.$ and $\left.k_{2}\right)$ has been adversely affected, without the same increase in $k_{5}$ as is seen in Tyr309Hco. In combination with the $\mathrm{pH}$ profiles that show that the changing protonation state of Hco309 affects turnover, this analysis establishes that the residue at position 309 is directly involved in both Michaelis complex formation and product release.

The possible rotamers of Hco309 are shown in Figure 6. The effect of this mutation on turnover may be explained by the fact that the phosphotriester substrates of PTEs are uncharged, unlike the 4-nitrophenolate leaving group, which is negatively charged at $\mathrm{pH}$ values above 7.1 . The negative charge associated with Hco309 will therefore electrostatically repel the negatively charged product more than the neutral substrate, thereby affecting product release more than substrate binding. These data, which could only be obtained using mutagenesis with 


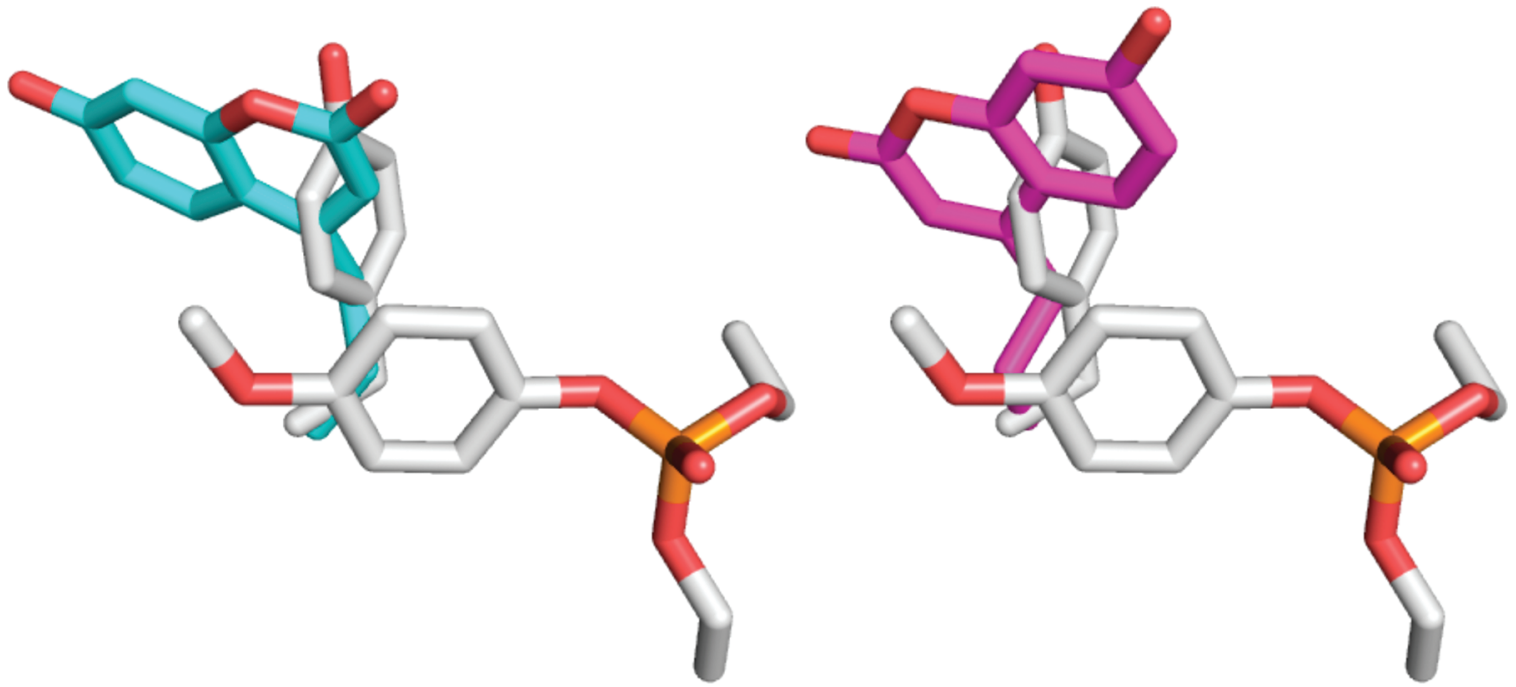

Figure 6. Potential rotamers (without steric clashes to other amino acid side chains or substrate) of Hco309 relative to the substrate diethylmethoxyphenylphosphate and Tyr309 in the wild-type protein based on the crystal structure of the enzyme-substrate complex (PDB accession code 2R1N). The topology of Hco, bond restraints, and angle restraints were produced using the PRODRG server. ${ }^{47}$

$u A A s$, highlight the importance of noncovalent interactions in ES and EP complexes and the trade-off between efficient binding and fast turnover in enzymes.

In principle, the increased turnover rate observed in the Tyr309Hco variant could also result from an alteration in the catalytic mechanism in which the hydroxyl group of Hco acts as a nucleophile in the hydrolysis of paraoxon because it will be positioned in the vicinity of the hydrolyzable $\mathrm{P}-\mathrm{O}$ bond. Indeed, lysine and tyrosine residues have been shown to be responsible for the stoichiometric breakdown of organophosphates by albumin. ${ }^{51}$ In this scenario, Hco309 would become phosphorylated by the substrate, followed by slow regeneration of the enzyme through water-mediated dephosphorylation. Because the spectrophotometric assay only detects the release of 4-nitrophenol/4-nitrophenolate, we performed liquid chromatography/mass spectrometry to test for simultaneous release of both diethyl phosphate and 4-nitrophenolate, to establish whether both products were released. This was confirmed (Figure 3 of the Supporting Information), consistent with the rapid rate of substrate turnover, which is incompatible with any slow dephosphorylation of Hco that would be necessary to regenerate the free enzyme following any Hco-mediated hydrolysis of paraoxon.

Comparison to Computer Simulation. The altered $K_{\mathrm{M}}$ values of the variants presented here suggest that the residue at position 309 is directly involved in the formation of the Michaelis complex ( $k_{1}$ and $k_{2}$ in eq 2$)$ during the catalytic cycle, while the altered $k_{\text {cat }}$ values also suggest that it is involved in interactions with the 4-nitrophenolate product of paraoxon hydrolysis during the rate-limiting product release step $\left(k_{5}\right)$. Previous computer simulations suggested that, to acquire the transition state geometry for nucleophilic attack from the $\mu$-hydroxo bridge between the metals, paraoxon moves closer to the binuclear metal center to become properly aligned for $\mathrm{S}_{\mathrm{N}} 2$ attack and loses much of its aromatic interaction with Tyr309, ${ }^{31,32}$ and that this rearrangement contributes to an energy barrier in the order of $18.7 \mathrm{kcal} / \mathrm{mol}$, partly due to steric clashes with Tyr309. ${ }^{32}$ Other studies have omitted Tyr309 and other

(51) Lockridge, O.; Schopfer, L. M. Chem. Biol. Interact. 2010, 187, 344 348. active site residues altogether. ${ }^{33}$ The experimentally determined activation energy for the rate limiting step, product release, is of the order of $12 \mathrm{kcal} / \mathrm{mol},{ }^{27}$ meaning the energy barrier for the chemical step must be even lower. The results presented here, as well as previous analysis of alanine and phenylalanine mutants of Tyr309, ${ }^{19,29}$ are more consistent with crystal structure snapshots obtained during the catalytic cycle ${ }^{22,27}$ than recent simulations; because both Tyr309 and the bulkier $u A A$ s analyzed here support fast substrate turnover and directly affect $K_{\mathrm{M}}$ and $k_{\text {cat }}$, they are unlikely to impede formation of the transition state, and instead most likely contribute to productive alignment of the substrate for in-line attack from an alternative nucleophilic water/hydroxyl to the $\mu$-hydroxo bridge.

Engineering Enhanced Activity in arPTE with $\boldsymbol{u A A s}$. The $k_{\text {cat }}$ values for wild-type, Tyr309Mco, and Tyr309Hco arPTEs for paraoxon hydrolysis at $\mathrm{pH} 8.5$ are 510,910 , and $3990 \mathrm{~s}^{-1}$, respectively (Table 2); an 8-fold increase in the turnover rate for the Tyr309Hco variant over that of the wild-type enzyme. The magnitude of this increase is even greater at $\mathrm{pH}$ values above 8.5 (11-fold at $\mathrm{pH} 10$ ). However, although $k_{\text {cat }}$ is increased, the ratio of $k_{\mathrm{cat}} / K_{\mathrm{M}}$, also known as the specificity constant and often considered to be a measure of catalytic efficiency, is essentially unchanged for the Tyr309Hco variant compared to the wild-type enzyme. As discussed above and shown in Scheme 2 and eq 2 , the value of $k_{\text {cat }} / K_{\mathrm{M}}$ is informative and valuable because it incorporates most of the different rate constants of the catalytic cycle. However, the present data also show that $k_{\text {cat }} / K_{\mathrm{M}}$ is not well suited for evaluating catalytic improvements in enzymes: despite wild-type and Tyr309Hco arPTE having equal $k_{\text {cat }} / K_{\mathrm{M}}$ values, the Tyr309Hco variant is a substantially more effective catalyst than the wild-type enzyme at all substrate concentrations above $10 \mu \mathrm{M}$ (Figure 7), which is less than one tenth of its $K_{\mathrm{M}}$ and much lower than any substrate concentration that is typically used during laboratory protein engineering/evolution experiments $(100-500 \mu \mathrm{M})$. In field applications, concentrations higher than $10 \mu \mathrm{M}$ are regularly encountered in some agricultural waste waters (e.g., spent animal and horticultural dip liquors). 


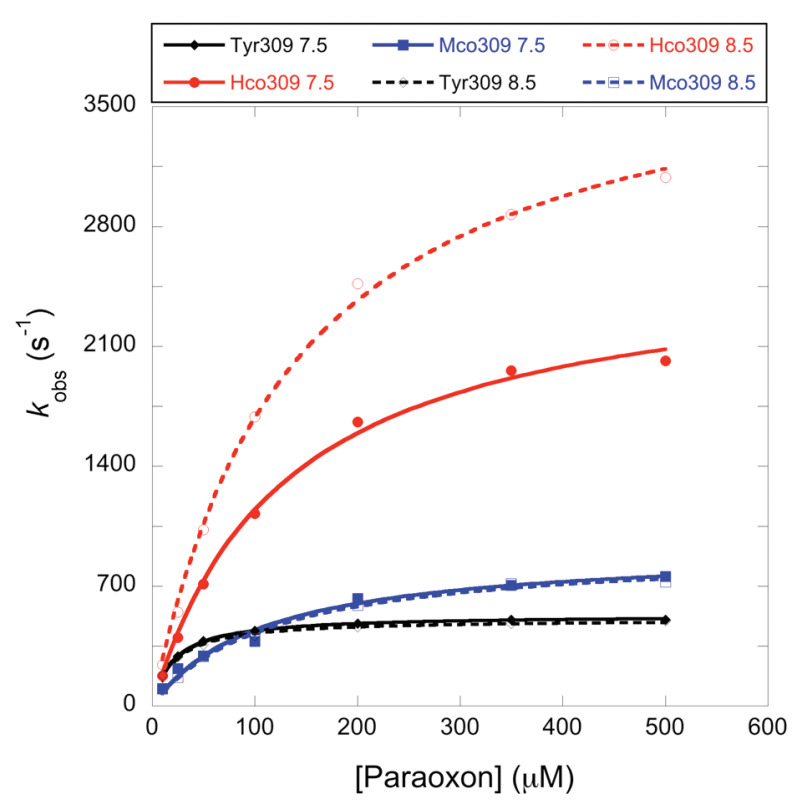

Figure 7. Comparison of reaction velocities of wild-type arPTE and variants for hydrolysis of paraoxon at $\mathrm{pH} 7.5$ and 8.5.

Others have previously highlighted the unsuitability of $k_{\text {cat }} /$ $K_{\mathrm{M}}$ as an accurate measure of catalytic efficiency, ${ }^{52-54}$ particularly in the context of protein engineering. Put simply, these results also support the notion that the best means to evaluate the effectiveness of an enzyme catalyst for a particular reaction is to determine the rate of substrate turnover, or the maximum amount of substrate that is turned over, at defined substrate concentrations. By this measure, it is clear that, for substrate concentrations greater than $10 \mu \mathrm{M}$, the Tyr309Hco variant is a considerably improved catalyst when compared with the wildtype enzyme.

Impressive improvements in the turnover rates of enzymes have been achieved through protein engineering using both $u A A s$ and natural $A A \mathrm{~s}$, targeting inefficient promiscuous, or non-native, activities. ${ }^{55-57}$ In contrast, improving the efficiency at which an enzyme catalyzes a reaction with its native substrate is very difficult to achieve. ${ }^{27,37,58}$ Despite the fact that paraoxon was only present in the environment for ca. 40 years before the discovery of the PTEs, ${ }^{13,14}$ several mechanistic studies have shown them to be highly optimized for catalysis of paraoxon hydrolysis. ${ }^{20,25,27}$ Their natural evolutionary optimization is also seen in our inability to significantly increase the rate of paraoxon turnover by arPTE in the laboratory either through screening

(52) Ceccarelli, E. A.; Carrillo, N.; Roveri, O. A. Trends Biotechnol. 2008, 26, 117-118.

(53) Eisenthal, R.; Danson, M. J.; Hough, D. W. Trends Biotechnol. 2007, $25,247-249$.

(54) Fox, R. J.; Clay, M. D. Trends Biotechnol. 2009, 27, 137-140.

(55) Aharoni, A.; Gaidukov, L.; Khersonsky, O.; Gould, S. M.; Roodveldt, C.; Tawfik, D. S. Nat. Genet. 2005, 37, 73-76.

(56) Bloom, J. D.; Arnold, F. H. Proc. Natl. Acad. Sci. U.S.A. 2009, 106, 9995-10000.

(57) Jackson, J. C.; Duffy, S. P.; Hess, K. R.; Mehl, R. A. J. Am. Chem. Soc. 2006, 128, 11124-11127.

(58) Mueller-Cajar, O.; Whitney, S. M. Biochem. J. 2008, 414, 205-214. hundreds of thousands of random mutants ${ }^{27,37}$ or via rational mutation of Tyr309 to other hydrophobic residues (Leu, Phe, Trp; Table 2). Griffiths and Tawfik ${ }^{34}$ previously isolated a mutant of $p d$ PTE with a 3.6-fold increase in specific activity at a concentration of $250 \mu \mathrm{M}$ paraoxon, although this variant was identified through the impressive technical achievement of screening $3.7 \times 10^{7}$ mutants by in vitro compartmentalization; here we have increased the specific activity of arPTE at 250 $\mu \mathrm{M} 5.5$-fold with a single unnatural point mutation. These results highlight the potential that man-made amino acids hold for accessing functional space that is not available during natural evolution and engineering with natural amino acids, showing that the already exciting prospects for de novo design of enzyme catalysts $^{59-61}$ may be greatly enhanced through the use of unnatural amino acids.

\section{Summary}

In this work two $u A A s, \mathrm{Mco}$, and Hco, were introduced into arPTE in place of Tyr309. The use of these $u A A$ s allowed the detailed analysis of the interaction between enzyme and substrate during formation of the Michaelis complex and product release, and established that the residue at position 309 is directly involved in both of these processes. The data imply that the complexes seen in recent crystal structures of the enzyme captured during substrate turnover are most likely accurate and highlight the importance of nonchemical steps for the maintenance of fast substrate turnover during the catalytic cycles of enzymes. The potential value of $u A A \mathrm{~s}$ in protein engineering is emphasized by the observation that the single site Tyr309Hco mutation reported here produced a greater increase in activity than has been obtained from screening of many thousands of variants created using natural amino acids.

Acknowledgment. We thank Prof. P. Schultz (The Scripps Research Institute, USA) for the vectors pSUP-CouRS-D8 and pSUP-MjTyrRS-6TRN, Prof. Y. Mo (University of Western Michigan, USA) for coordinates from computer simulations and Dr P. Campbell (CSIRO Entomology, Australia) for assistance with tryptic digest mass spectrometry. Financial support by CSIRO's Emerging Science Initiative (I.U.), and the Australian Research Council, including an Australian Research Fellowship to K.O., is gratefully acknowledged.

Supporting Information Available: Analytical and spectral characterization data for the synthesis of $u A A$ s (Hco and Mco) and other information. This material is available free of charge via the Internet at http://pubs.acs.org.

\section{JA106416G}

(59) Jiang, L.; Althoff, E. A.; Clemente, F. R.; Doyle, L.; Rothlisberger, D.; Zanghellini, A.; Gallaher, J. L.; Betker, J. L.; Tanaka, F.; Barbas, C. F., 3rd; Hilvert, D.; Houk, K. N.; Stoddard, B. L.; Baker, D. Science 2008, 319, 1387-1391.

(60) Khersonsky, O.; Rothlisberger, D.; Dym, O.; Albeck, S.; Jackson, C. J.; Baker, D.; Tawfik, D. S. J. Mol. Biol. 2010, 396, 1025-1042.

(61) Rothlisberger, D.; Khersonsky, O.; Wollacott, A. M.; Jiang, L.; DeChancie, J.; Betker, J.; Gallaher, J. L.; Althoff, E. A.; Zanghellini, A.; Dym, O.; Albeck, S.; Houk, K. N.; Tawfik, D. S.; Baker, D. Nature 2008, 453, 190-195. 